\title{
Catecholaminergic Properties of Cholinergic Neurons and Synapses in Adult Rat Ciliary Ganglion
}

\author{
Story C. Landis, ${ }^{1}$ Patrick C. Jackson, ${ }^{1, a}$ John R. Fredieu, ${ }^{1, b}$ and Jean Thibault ${ }^{2}$ \\ 'Department of Neurobiology, Harvard Medical School, Boston, Massachusetts 02115, and ${ }^{2}$ College de France, Paris, \\ France
}

Parasympathetic neurons of the ciliary ganglion are innervated by preganglionic cholinergic neurons whose cell bodies lie in the brain stem; the ganglion cells in turn provide cholinergic innervation to the intrinsic muscles of the eye. Noradrenergic innervation of the iris is supplied by sympathetic neurons of the superior cervical ganglion. Using immunocytochemical and histochemical techniques, we have examined the ciliary ganglion of adult rats for the expression of cholinergic and noradrenergic properties. As expected, the postganglionic ciliary neurons possessed detectable levels of choline acetyltransferase immunoreactivity (ChATIR). Unexpectedly, many ciliary neurons also exhibited immunoreactivity for tyrosine hydroxylase (TH-IR). Some had dopamine $\beta$-hydroxylase-like (DBH-IR) immunoreactivity, but none contained detectable catecholamines, even after treatment with nialamide and L-DOPA. A sparse plexus of fibers exhibiting faint TH-IR was present in the irises of acutely sympathectomized rats. The terminals of preganglionic axons in the ciliary ganglion exhibited not only immunoreactivity for ChAT, but also for TH and contained stores of endogenous catecholamine. Neither ciliary neurons nor their preganglionic innervation accumulated detectable stores of exogenous catecholamines. Rats sympathectomized as neonates by treatment with 6-hydroxydopamine subsequently had a greater proportion of neurons possessing detectable TH-IR in the ciliary ganglion; both the TH-IR perikarya and their axons in the iris were more intensely immunofluorescent. TH-IR was present in the ciliary neuron cell bodies of mouse, guinea pig, and ferret. These species, however, lacked detectable TH-IR or catecholamine stores in preganglionic terminals. These observations indicate that mature, functionally cholinergic neurons from 2 different embryonic origins, postganglionic ciliary neurons derived from the neural crest and preganglionic neurons derived from the neural tube, display several catecholaminergic properties.

\footnotetext{
Received Oct. 10, 1986; revised Mar. 2, 1987; accepted Apr. 30, 1987.

This work was supported by USPHS Grants NS 02253 and NS 15549 and Training Grant NS07009 and was carried out during the tenure of an Established Investigatorship of the American Heart Association (S.C.L.) and with funds contributed in part by the Massachusetts Affiliate. We wish to thank Dr. Nancy Ip for performing tyrosine hydroxylase assays and Drs. David Potter, Bill Matthew, and Tom Jessell for critically reading the manuscript.

Correspondence should be addressed to Story C: Landis, Department of Pharmacology, Case Western Reserve Medical School, Cleveland, OH 44106.

a Present address: Department of Anatomy, Dalhousie University, Halifax, Nova Scotia, Canada.

b Present address: Department of Anatomy, Case Western University, Cleveland, $\mathrm{OH} 44106$.

Copyright (c) 1987 Society for Neuroscience $0270-6474 / 87 / 113574-14 \$ 02.00 / 0$
}

The developmental mechanisms responsible for these mixed transmitter phenotypes and the functional consequences remain to be elucidated.

The ciliary ganglion is classified as a parasympathetic ganglion based on anatomical, biochemical, and pharmacological criteria. The ganglion lies close to its target tissues, the iris and ciliary body; the preganglionic neurons lie in the brain stem (Warwick, 1954; Loewy et al., 1978; Johnson and Purves, 1981). In the cat, the mammal studied most extensively, the ganglion contains high levels of ChAT, reflecting enzyme present in both preganglionic terminals and postganglionic perikarya (Buckley et al., 1967). The postganglionic terminals in the iris contain high levels of ChAT (Ehinger et al., 1966) and ACh (Ehinger et al., 1970a). The pharmacology of transmission at both ganglionic (Langley and Anderson, 1892; Perry and Talesnik, 1953) and postganglionic synapses is cholinergic (Schaeppi and Koella, 1964; Ehinger et al., 1968).

According to the traditional view of the autonomic nervous system, postganglionic sympathetic neurons are noradrenergic, parasympathetic ones are cholinergic, and the preganglionic neurons of both divisions are uniformly cholinergic. Thus, the parasympathetic and functionally cholinergic neurons of the ciliary ganglion and their preganglionic inputs would not be expected to express catecholaminergic properties. A number of observations, however, make it clear that in the autonomic nervous system, neurotransmitter-related properties cannot be attributed singly or strictly on the basis of cell class. For example, in the sympathetic division, a minority population of postganglionic neurons are functionally cholinergic (Langley, 1891, 1922; Sjoqvist, 1963; Leblanc and Landis, 1986) and developing adrenergic sympathetic neurons can become cholinergic both in vitro (e.g., Johnson et al., 1976, 1980; Patterson and Chun, 1977; Landis, 1980; Potter et al., 1986) and in vivo (Landis and Keefe, 1983; Leblanc and Landis, 1986). Under certain conditions in vitro (Furshpan et al., 1976; Landis, 1976; Reichardt and Patterson, 1977; Higgins et al., 1981; Iacovitti et al., 1981; Potter et al., 1986) and in vivo (Siegel et al., 1982; Landis and Keefe, 1983), functionally cholinergic sympathetic neurons exhibit adrencrgic propertics. In the parasympathetic division of the autonomic nervous system, mature submandibular ganglion neurons contain dopamine- $\beta$-hydroxylase (DBH) enzyme activity and immunoreactivity (Coyle et al, 1974; Grzanna and Coyle, 1978). A small proportion of ciliary neurons in the chick embryo normally express tyrosine hydroxylase-immunoreactivity (TH-IR) and the proportion of these TH-IR neurons is significantly increased in cell culture (Iacovitti et al., 1985; Teitelman et al., 
1985). Finally, Bjorklund and colleagues (1985) have shown that ciliary terminals in the irises of adult rats acquire detectable levels of TH-IR following sympathectomy. In the course of other studies, we observed identical TH-IR fibers in the irises of rats sympathectomized at birth by treatment with 6-hydroxydopamine. In tracing the origin of these fibers, we found that the ciliary ganglia of normal as well as chronically sympathectomized adult rats contained significant numbers of TH-IR neurons. In addition, preganglionic terminals in the ciliary ganglion contained not only TH-IR, but also significant stores of catecholamine, most likely dopamine. A preliminary report of these results has appeared (Landis et al., 1983).

\section{Materials and Methods}

Animals. Adult albino rats were used in most experiments. In addition, ciliary ganglia from adult Long Evans hooded rats, albino and pigmented mice, albino guinea pigs, and pigmented ferrets were examined for both TH-IR and catecholamine histofluorescence. Some rats were acutely sympathectomized by surgical removal of the superior cervical ganglion and examined 2,4 , or $7 \mathrm{~d}$ after surgery. In addition, other rats were chemically sympathectomized as neonates or as adults by treatment with 6-hydroxydopamine; rat pups were injected with $100 \mathrm{mg} / \mathrm{kg}$ intraperitoneally (i.p.) daily for the first postnatal week and adults were injected with $100 \mathrm{mg} / \mathrm{kg}$ i.p. for $3 \mathrm{~d}$ and examined on the fourth (Clark et al., 1972; Finch et al., 1973). To increase endogenous stores of catecholamine, nialamide (100 mg/kg i.p. $3 \mathrm{hr}$ before death), a monoamine oxidase inhibitor, was injected either alone or in conjunction with L-DOPA (200 mg/kg i.p. $1 \mathrm{hr}$ before death). To assess qualitatively the ability of ciliary neurons and their innervation to take up and accumulate exogenous catecholamines, rats were injected i.p. with $\alpha$-methylnorepinephrine ( 1 or $10 \mathrm{mg} / \mathrm{kg} 30 \mathrm{~min}$ before death).

The ciliary ganglion was decentralized or removed surgically through an incision in the conjunctiva at the inferior pole of the globe of the eye. Bhunt separation of the medial and inferior rectus muscles exposed the oculomotor nerve within the orbit at the place where it branches to innervate these 2 muscles (see diagram in Jackson, 1986); the ciliary ganglion is located at this branch point and receives input from preganglionic axons running in the oculomotor nerve. Preganglionic inputs were severed by identifying the ganglion and cutting the oculomotor nerve approximately $5 \mathrm{~mm}$ centrally. In some cases, the ciliary ganglion was excised by removing the segment of the oculomotor nerve containing the ganglion. That the ganglion had been removed was verified by examination of a wet mount of the tissue piece with phase microscopy. Both operations led to a loss of the pupillary light reflex, indicating interruption of the parasympathetic motor pathway. Neither operation led to detectable ptosis, indicating that sympathetic outflow had not been affected. As a control, in some animals, ganglia were simply exposed as described above

Antisera. For immunocytochemical localization of ChAT, a mouse antiserum raised against ChAT purified from pig brain (Eckenstein et al., 1981) was used. For immunocytochemical localization of TH, in most experiments, the TH antiserum used was one generated against TH purified from a rat pheochromocytoma tumor (Thibault et al., 1981). This antiserum displayed a single precipitation line when tested against either purified TH or a $100,000 \times g$ supernatant from pheochromocytoma cells in an Ouchterlony double-diffusion assay. Further, when an immunoprecipitate was run on an SDS-acrylamide gel, a single major band with an apparent molecular weight of 62,000 was seen in addition to the immunoglobulin bands; a second minor band of 60,000 was a proteolytic product. In several experiments, other immunological probes for $\mathrm{TH}$ were used. A second $\mathrm{TH}$ antiserum used was obtained commercially (Eugene Tech International). This antiserum was generated against TH purified as a trypsin-digested form from bovine adrenal medulla and is similar if not identical in its properties to that generated by Dr. T. Joh and used extensively to localize TH (Joh and Ross, 1983). In addition, a mouse monoclonal antibody generated against TH purified from rat pheochromocytoma cells (the kind gift of Dr. Ann Acheson) was used (Rohrer et al., 1986). This antibody recognizes a single protein of the appropriate molecular weight on immunoblots of total protein from rat adrenal medulla and immunoprecipitates TH enzymatic activity from homogenates of bovine adrenal chromaffin cells. The DBH antiserum has been described previously (Grzanna et al., 1976). The phenylethanolamine $N$-methyl transferase (PNMT) antiserum was raised in rabbit against PNMT purified from bovine adrenal medulla and was obtained commercially (Eugene Tech International). Synaptic terminals were identified using a mouse monoclonal antibody that recognizes a synaptic vesicle antigen (Matthew et al., 1981).

Immunocytochemistry. Binding of the primary ChAT antiserum was visualized with a double-cycle peroxidase-antiperoxidase procedure (PAP; Sternberger et al., 1970; Ordronneau et al., 1981). Six-week-old rats were deeply anesthetized with ether and perfused through the heart for $10 \mathrm{~min}$ with $4 \%$ paraformaldehyde in $0.1 \mathrm{~m}$ phosphate buffer, $\mathrm{pH}$ 7.3 , containing $15 \%$ by volume of a saturated aqueous solution of picric acid. The ciliary ganglia were dissected along with a segment of the oculomotor nerve and immersed for an additional $50 \mathrm{~min}$ in the same fixative solution. The ganglia were rinsed several times with $0.1 \mathrm{M}$ phosphate buffer and then equilibrated with $30 \%$ sucrose in phosphate buffer. In some cases, $20 \mu \mathrm{m}$ cryostat sections were cut, while in others, the ganglia were frozen and thawed and then processed as whole mounts. The sections or ganglia were incubated overnight at room temperature in mouse anti-ChAT (the kind gift of F. Eckenstein, Harvard Medical School, Boston), diluted 1:1000 in buffer containing 0.1 м Tris buffer, pH 7.3, 150 mm sodium chloride, $1 \%$ BSA, and $5 \%$ Triton X-100. The tissue was rinsed several times with incubation buffer, then incubated in affinity-purified goat anti-mouse immunoglobulins diluted $1: 40$ in incubation buffer containing $10 \%$ rat serum. After rinsing in incubation buffer, the sections were incubated in a mouse monoclonal antibody to a PAP complex diluted $1: 80$ in incubation buffer containing rat serum. The sections were then cycled a second time through the goat antimouse antiserum and mouse PAP. The sections were reacted with diaminobenzidine and peroxide in $0.1 \mathrm{M}$ Tris, mounted on gelatin-coated slides, dehydrated, and coverslipped with Permount. No staining was observed if the primary antiserum was omitted or if preimmune mouse serum was substituted for the primary antiserum.

For TH staining of ciliary ganglion, adult rats were deeply anesthetized and perfused with $4 \%$ paraformaldehyde in $0.1 \mathrm{M}$ phosphate buffer, $\mathrm{pH}$ 7.3 , for $10 \mathrm{~min}$. The ciliary ganglia were dissected out, left in fixative for an hour, rinsed in buffer, and equilibrated with 30\% sucrose in phosphate buffer overnight. Ten micron cryostat sections were mounted on gelatin-coated slides, rinsed with phosphate buffer, and incubated with primary antiserum (diluted 1:1000; 1:100 for the purchased antiserum) in humid chambers overnight at room tempcraturc. Following incubation, the sections were rinsed and incubated for $2 \mathrm{hr}$ with tetramethylrhodamine isothiocyanate-conjugated goat anti-rabbit immunoglobulin. The sections were rinsed again with phosphate buffer, mounted in glycerol : ethanol (1:1), and examined with epifluorescence. No staining was observed if normal rabbit antiserum was substituted for $\mathrm{TH}$ antiserum or if the TH antiserum generated against the rat pheochromocytoma tumor was absorbed prior to use with purified TH. Absorption controls were not performed on the second antiserum. For the mouse monoclonal antibody generated against TH, binding of the primary antibody was visualized with fluorescein-conjugated goat antimouse. For comparison, sympathetic superior cervical ganglia were removed and processed for TH-IR. To localize DBH-IR, $10 \mu \mathrm{m}$ cryostat sections of paraformaldehyde-fixed ciliary ganglia were incubated with guinea pig anti-DBH (the kind gift of R. Grzanna, Johns Hopkins, Baltimore, MD) diluted 1:500 overnight in humid chambers at $4^{\circ} \mathrm{C}$. The sections were rinsed with phosphate buffer and incubated for $2 \mathrm{hr}$ at room temperature with tetramethylrhodamine isothiocyanate-conjugated goat anti-guinea pig immunoglobulin. To examine the possible colocalization of TH and DBH, sections were incubated sequentially in the DBH antiserum raised in guinea pig, fluorescein-conjugated goat anti-guinea pig immunoglobulins, the TH antiserum raised in rabbit, and then rhodamine-conjugated goat anti-rabbit immunoglobulin. To localize PNMT-IR, sections of ciliary ganglia were incubated in a commercially available primary rabbit antiserum raised against PNMT and diluted 1:20. Sections of adrenal medulla reacted in the same manner showed many intensely immunoreactive chromaffin cells. The synaptic vesicle antigen was localized in $10 \mu \mathrm{m}$ cryostat sections of ciliary ganglia from $4 \%$ paraformaldehyde-fixed adult rats. Binding of the primary antibody (the kind gift of W. Matthew, Harvard Medical School, Boston, MA) was visualized with fluorescein-conjugated goat anti-mouse. Incubations with the TH, DBH, and PNMT antisera and the monoclonal antibody directed against synaptic vesicle antigen were carried out in a solution containing $0.5 \mathrm{M} \mathrm{NaCl}, 0.01 \mathrm{~m}$ phosphate buffer, $\mathrm{pH} 7.3,0.2 \%$ Triton X-100, $0.1 \%$ sodium azide, and 5\% BSA. 

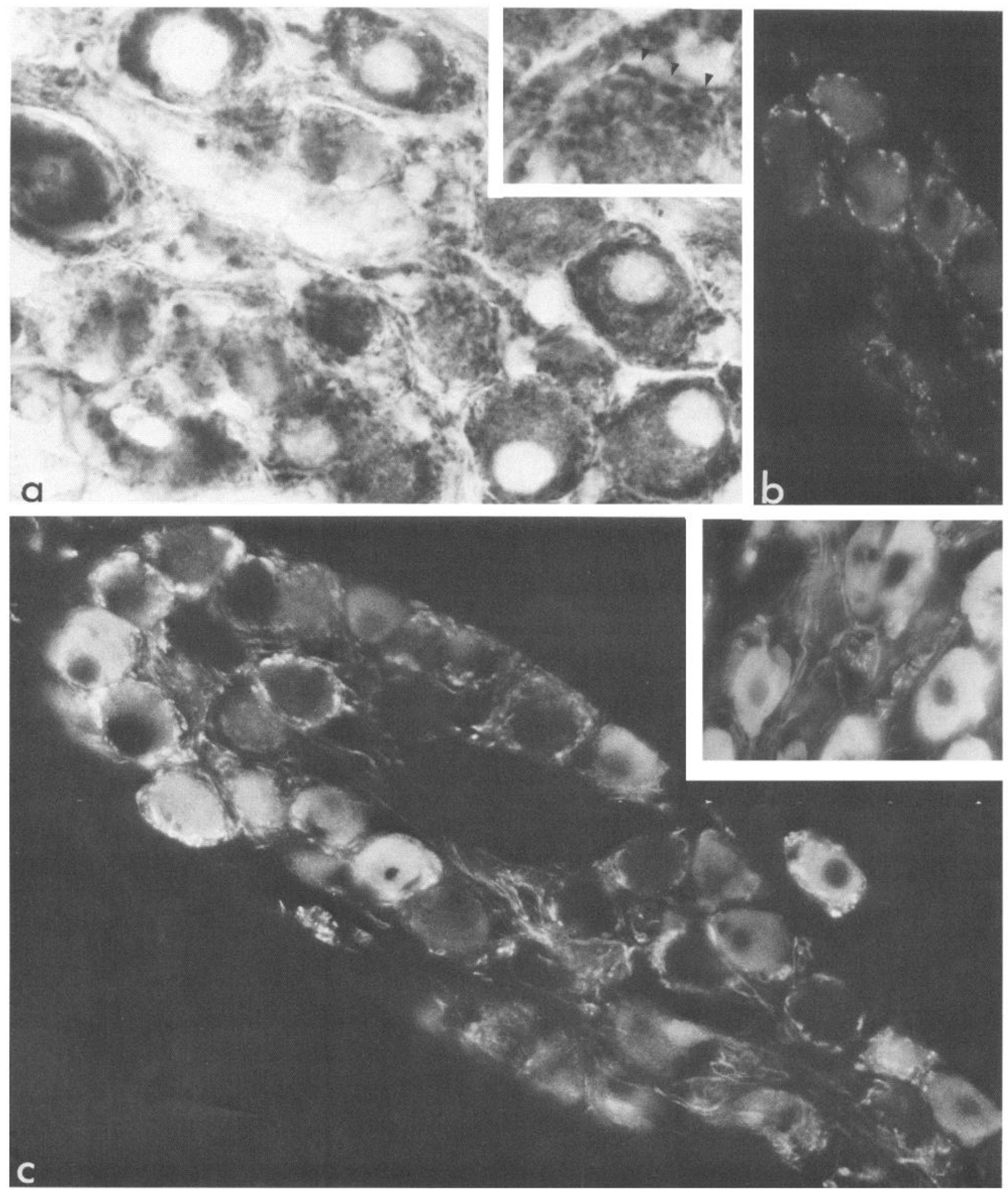

Figure 1. a, Light micrograph of a ciliary ganglion from an adult rat labeled with choline acetyltransferase antiserum visualized with peroxidaseantiperoxidase immunocytochemistry. All principal neurons are labeled. The reaction product has a mottled appearance due to the superimposition of densely labeled terminals on a less intensely labeled cytoplasm in this $20 \mu \mathrm{m}$ section. $\times 800$. Inset $(\times 1000)$, One neuron is shown at higher magnification. Arrows indicate 3 boutons. $b$, Light micrograph of a ciliary ganglion from an adult rat labeled with a monoclonal antibody recognizing a synaptic vesicle antigen and visualized with goat anti-mouse fluorescein. The faintly immunoreactive neuronal cell bodies are surrounded by brightly immunofluorescent preganglionic terminals. Since this section is $10 \mu \mathrm{m}$ thick, fewer terminals are present than in $a$. $\times 450$. $c$, Light micrograph of a ciliary ganglion from an adult rat labeled with anti-TH serum visualized with a rhodamine-conjugated secondary antiserum. Many labeled and some unlabeled neuron cell bodies are present. Perikarya, both labeled and unlabeled, are surrounded by immunoreactive terminals. Inset, Light micrograph of a superior cervical sympathetic ganglion labeled with anti-TH serum. All the neurons in the field are immunoreactive. The intensity of immunofluorescence of the most intensely fluorescent ciliary neurons is similar to that of the sympathetic principal neurons. $\times 450$. 

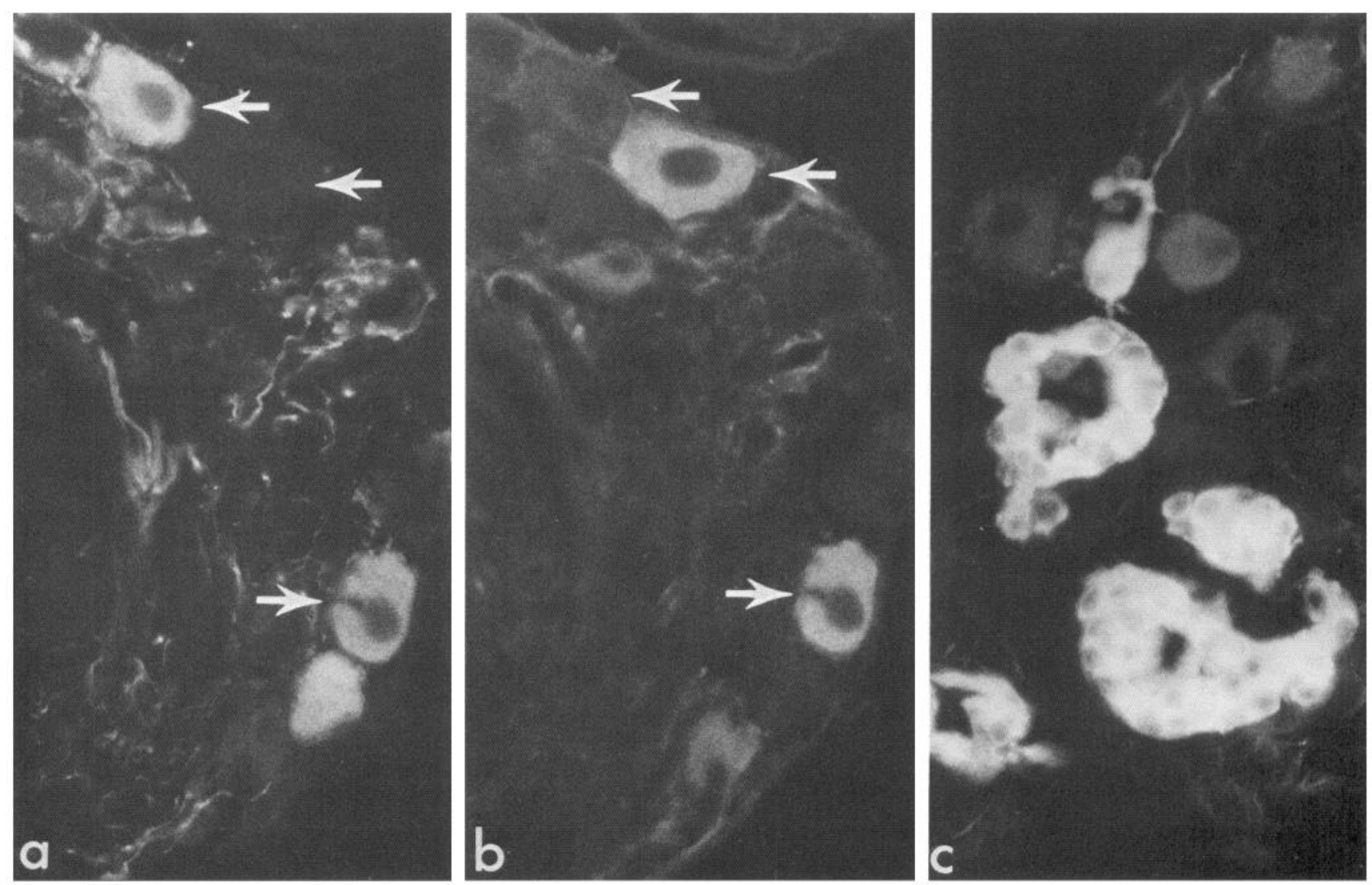

Figure 2. Light micrographs of a section from adult rat ciliary ganglion doubly labeled for TH and DBH. $a$, The immunofluorescence represents labeling with anti-TH rabbit serum visualized with rhodamine-conjugated goat anti-rabbit serum. $b$, The immunofluorescence represents labeling with anti-DBH guinea pig serum visualized with fluorescein-conjugated goat anti-guinea pig serum. The upper arrow indicates a neuron immunoreactive for TH but not DBH; the middle arrow indicates a neuron immunoreactive for DBH but not $\mathrm{TH}$, while the lower arrow indicates a neuron immunoreactive for both synthetic enzymes. No DBH immunoreactivity is detectable in the preganglionic terminals. $\times 450$. $c$, Light micrograph of a ciliary ganglion of an adult rat labeled with anti-TH serum. Several clumps of small intensely TH-immunoreactive cells are present. During printing, the micrograph has been overexposed to reveal details of these cells, and consequently, the immunoreactivity present in the adjacent principal neurons is barely detectable. $\times 450$.

The ultrastructural localization of TH-IR was determined using the PAP method (Sternberger et al., 1970). Rats were perfused with $4 \%$ paraformaldehyde and $0.05 \%$ glutaraldehyde in $0.1 \mathrm{M}$ phosphate buffer. Ciliary ganglia were dissected out, stored in fixative for an hour, rinsed with phosphate buffer overnight, and embedded in $4 \%$ agar. Slices, 150 $\mu \mathrm{m}$ thick, were obtained with a Smith-Farquhar tissue chopper and incubated overnight at room temperature in TH antiserum (1:2000). The slices were rinsed with phosphate buffer, incubated in 1:40 goat anti-rabbit immunoglobulin, rinsed with phosphate buffer, incubated in 1:80 rabbit PAP, rinsed with phosphate buffer, and reacted for peroxidase in $0.1 \mathrm{~m}$ Tris, $\mathrm{pH} 7.5$, containing diaminobenzidine $(0.5 \mathrm{mg} /$ $\mathrm{ml}$ ) and hydrogen peroxide $(0.006 \%)$. Azide was omitted from all but the primary antibody incubation. The tissue slices were then further fixed in $3 \%$ glutaraldehyde in $0.1 \mathrm{M}$ phosphate buffer, rinsed, osmicated, stained en bloc with uranyl acetate, dehydrated with ethanol, and embedded in Epon. Thin sections were examined without further staining.

Two methods were used to examine TH-IR in the iris. In some experiments, unfixed irides were stretched onto clean slides and fixed by immersion in $4 \%$ paraformaldehyde in $0.1 \mathrm{M}$ phosphate buffer for an hour. The slides were then rinsed, equilibrated with $30 \%$ sucrose in phosphate buffer, and then freeze-thawed twice to enhance penetration. The iris stretch preparations were then treated as described above. In other experiments, irides were dissected from paraformaldehyde-perfused rats, rinsed, and equilibrated in $30 \%$ sucrose. The irides were cut into thirds, stacked, and flat-frozen in Tissue-Tek on cryostat chucks. Ten micron sections were cut, mounted on gelatin-coated slides, and processed as described above.

Catecholamine localization. Sections were prepared according to the glyoxylic acid method of de la Torre (1980). Ciliary ganglia were freshfrozen. Ten micrometer sections were cut and dipped in a solution containing $1 \%$ glyoxylic acid, $0.2 \mathrm{~m}$ postassium phosphate buffer, $\mathrm{pH}$ 7.4 , and $0.2 \mathrm{M}$ sucrose. The sections were air-dried, heated at $95^{\circ} \mathrm{C}$ for $2.5 \mathrm{~min}$, coverslipped with paraffin oil, and viewed with epifluorescence and a catecholamine filter set.

For ultrastructural analysis of catecholamine localization, ciliary ganglia were dissected out and fixed by immersion in $4 \%$ potassium permanganate in $0.1 \mathrm{~m}$ phosphate buffer for $1 \mathrm{hr}$ on ice. The ganglia were then rinsed with acetate buffer, stained en bloc with uranyl acetate in acetate buffer, dehydrated, and embedded in Epon. Thin sections were examined without additional staining.

\section{Results}

The adult ciliary ganglion contained approximately 125 neurons, and virtually all of these exhibited immunoreactivity for ChAT (Fig. 1a); only occasional neurons (less than 1\%) lacked detectable ChAT-IR. Following immunocytochemical localization of ChAT-IR, the ciliary neurons possessed a mottled appearance due to the superimposition of intensely stained preganglionic terminal boutons on less intensely immunoreactive neuron cell bodies. The perisomatic distribution of preganglionic terminals was clearly revealed by a monoclonal antibody that binds to a synaptic vesicle antigen (Fig. $1 b$ ).

Many principal ciliary neurons expressed TH immunoreactivity (Figs. $1 c, 2 a, 3 b$ ). The TH-IR neurons were found dis- 

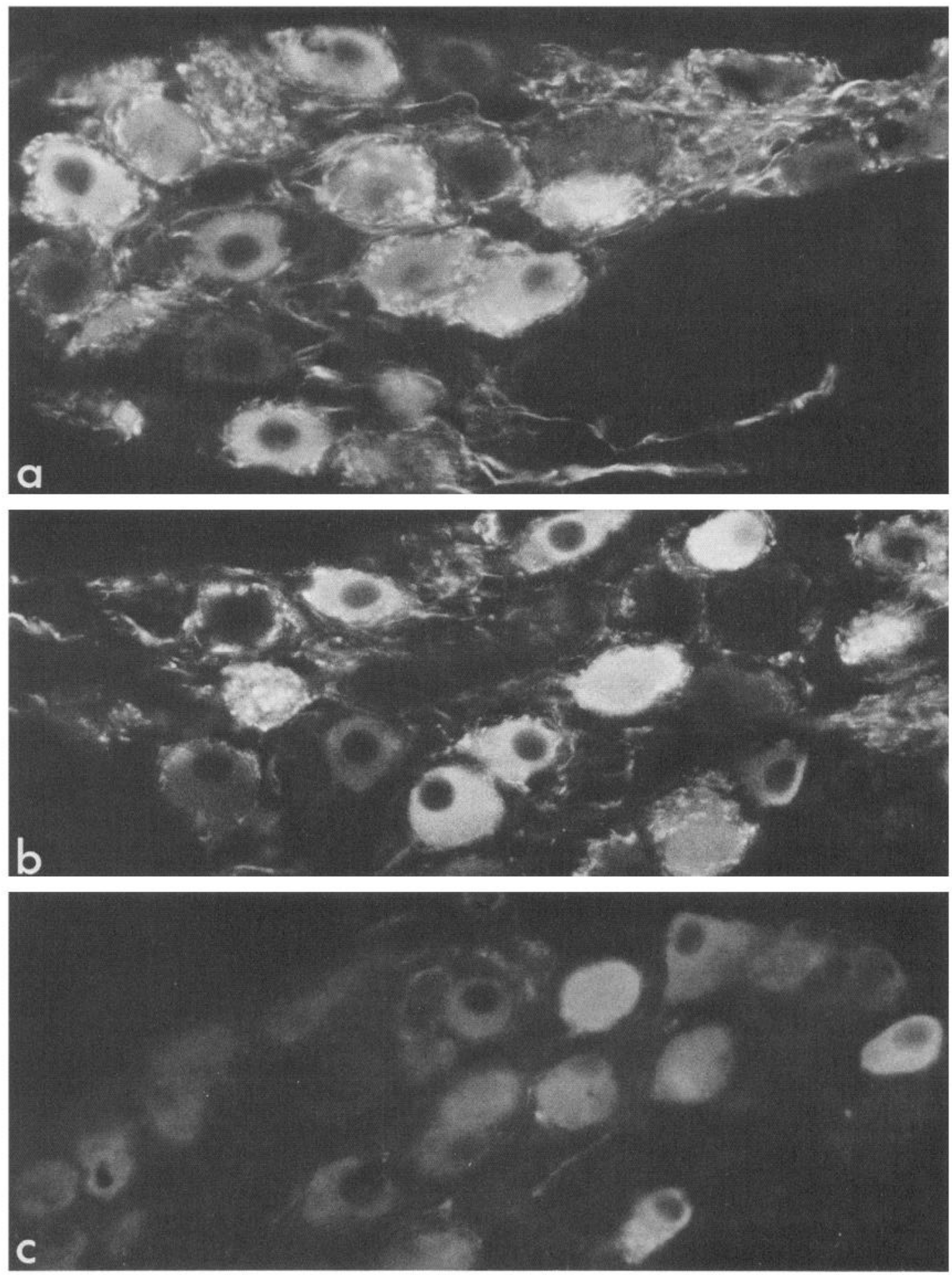

Figure 3. a, Light micrograph of a ciliary ganglion of an adult rat sympathectomized at birth by multiple injections of 6-hydroxydopamine. A greater proportion of TH-IR neurons are present in the ganglia of chronically sympathectomized animals, and the TH immunofluorescence appears more intense than in control animals. $\times 560 . b$, Light micrograph of a ciliary ganglion of an adult rat surgically sympathectomized $4 \mathrm{~d}$ previously. Removal of the ipsilateral superior cervical ganglion did not eliminate the TH-IR plexus surrounding the ciliary ganglion neurons. $\times 450 . c$, Light micrograph of a ciliary ganglion of an adult rat $4 \mathrm{~d}$ after section of the oculomotor nerve in which course the preganglionic axons. The TH-IR plexus has disappeared, and the intensity of TH immunofluorescence in the cell bodies is reduced. $\times 450$.

tributed throughout the ganglion, and the immunofluorescence in positive cells varied from very bright to just detectable. The intensely TH-IR neurons in the ciliary ganglion were equally as immunoreactive as sympathetic principal neurons in the su- perior cervical ganglion (Fig. 1c, inset). In normal adult rats, the proportion of neurons in the ciliary ganglion that expressed detectable TH-IR varied from 25 to $40 \%$. This variability could reflect real differences in the expression of TH-IR or experi- 

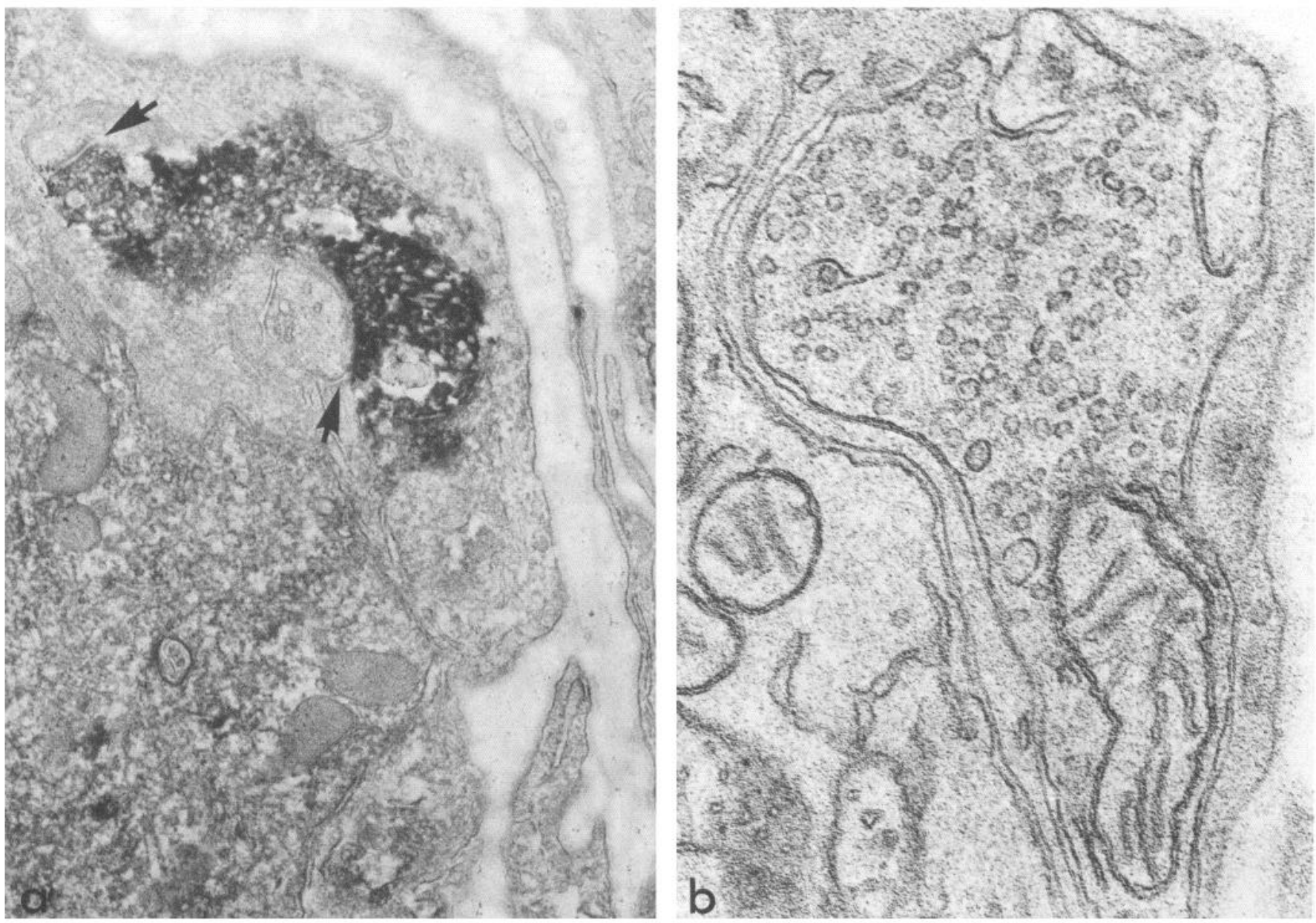

Figure 4. $a$, Electron micrograph of adult rat ciliary ganglion labeled with anti-TH serum visualized by peroxidase-antiperoxidase. A portion of a labeled postganglionic neuron is present, and a labeled presynaptic bouton forms synapses with 2 somatic processes $($ arrows). $\times 37,000$. $b$, Electron micrograph of adult rat ciliary ganglion following fixation with potassium permanganate. No small granular vesicles are evident in the presynaptic bouton. $\times 37,000$.

mental differences in the efficiency of detection of TH-IR in different preparations. Some ciliary ganglia also contained clusters of small intensely TH-IR cells (Fig. $2 c$ ) resembling the small intensely fluorescent or SIF cells present in sympathetic ganglia.

Immunoreactivity for $\mathrm{DBH}$, a second enzyme in the catecholamine synthetic pathway, was localized using guinea pig anti-rat adrenomedullary DBH. Approximately $10 \%$ of the neuronal cell bodies were positive for DBH-IR (Fig. $2 b$ ). When the same section was stained for both TH-IR (Fig. $2 a$ ) and DBHIR (Fig. $2 b$ ) using different fluorochromes to localize binding of the TH and DBH antisera raised in rabbit and guinea pig, respectively, approximately $3 \%$ of ciliary neurons were positive for both TH-IR and DBH-IR. However, many TH-IR neurons did not manifest DBH-IR, and some DBH-IR neurons did not manifest TH-IR. These results suggest that the TH-IR and DBHIR were not necessarily colocalized. No PNMT-IR was evident in ciliary neurons.

In addition to the TH-IR present in neuronal perikarya in the ciliary ganglion, most neurons were surrounded by a brightly TH immunofluorescent calycx. The TH-IR boutons corresponded in location and density to boutons visualized with either ChAT antiserum or a monoclonal antibody that recognizes synaptic vesicles (Fig. 1, $a-c$ ). No DBH-IR was detectable in the boutons (Fig. $2 b$ ). The TH-IR axonal plexus surrounding the neuronal perikarya disappeared following section of the oculomotor nerve central to the ganglion (Fig. $3 c$ ). This procedure resulted in the loss of the pupillary light reflex and of all terminals within the ganglion labelled by the monoclonal antibody recognizing the synaptic vesicle antigen. The TH-IR boutons were unaffected by removal of the ipsilateral superior cervical ganglion $4 \mathrm{~d}$ before analysis (Fig. $3 b$ ). These observations strongly suggest that the TH-IR fibers in the ciliary ganglion were preganglionic axons and not sympathetic in origin. Indeed, when TH-IR was localized at the ultrastructural level with PAP techniques, presynaptic profiles as well as neuronal cell bodies contained reaction product (Fig. $4 a$ ). It is of interest that following removal of the preganglionic input by cutting the oculomotor nerve, the intensity of TH-IR in the ciliary neuron cell bodies decreased. In the superior cervical ganglion, TH activity and TH-IR are increased by preganglionic stimulation (Zigmond and Bowers, 1981), and following decentralization, TH activity has been reported to decrease (Hendry et al., 1973).

To determine whether either the ciliary neurons or the preganglionic axons contained detectable endogenous catecholamines, $10 \mu \mathrm{m}$ cryostat sections from freshly frozen ciliary ganglia were reacted with glyoxylic acid to demonstrate catecholamine histofluorescence. No catecholamine fluorescence was observed in principal neuron cell bodies of normal 
adult rats (Fig. 5a). Treatment of adult rats with nialamide to inhibit monoamine oxidase (Fig. $5 b$ ) or with nialamide and L-DOPA (Fig. 5c), a precursor for aromatic L-amino acid decarboxylase, failed to yield detectable levels of catecholamine in ganglion cell neurons. These observations suggest that ciliary neurons contain little or no aromatic L-amino acid decarboxylase. SIF cells, presumably corresponding to the small intensely TH-IR cells, were observed in some ganglia.

In all ciliary ganglia, catecholamine fluorescence was observed surrounding ganglion cell bodies (Fig. $5 a$ ). The distribution was similar to that of the preganglionic axons exhibiting TH-IR. As was the case for the TH-IR fibers, the catecholamine fluorescent plexus in the ganglion was not affected by removal of the ipsilateral superior cervical ganglion but disappeared after the oculomotor nerve was cut. Treatment with nialamide or nialamide together with L-DOPA significantly increased the fluorescence in the preganglionic axonal plexus (Fig. $5, b, c$ ). When the ciliary ganglion was fixed with potassium permanganate, which yields an electron-dense precipitate in synaptic vesicles containing norepinephrine but not those containing dopamine (Hökfelt, 1968; Hökfelt and Jonsson, 1968), and examined with the electron microscope, no small granular vesicles were present in the preganglionic terminals (Fig. $4 b$ ). The absence of both DBH-IR and small granular vesicles indicates that the catecholamine stored in the preganglionic terminals is dopamine.

In addition to the catecholamine plexus within the ciliary ganglion, catecholamine-containing fibers exhibiting the morphological characteristics of peripheral sympathetic terminals were often observed innervating adjacent blood vessels. These fibers disappeared after removal of the ipsilateral superior cervical ganglion but not after cutting the preganglionic nerve.

The ability of ciliary neurons and preganglionic terminals to accumulate exogenous catecholamine was assayed qualitatively. Following injection of $\alpha$-methylnorepinephrine, no catecholamine fluorescence was detectable in the ciliary neuron cell bodies, and the fluorescence present in the preganglionic terminals was not appreciably increased. A second assay took advantage of the toxicity of 6-hydroxydopamine, a norepinephrine congener that is accumulated via the high-affinity catecholamine uptake system. When neonatal rats were chemically sympathectomized with 6-hydroxydopamine and examined as adults, the experimental ciliary ganglia contained the same number of neurons and the same density of preganglionic terminals as control ganglia. Further, these chronically sympathectomized rats did not exhibit diminished TH-IR in either the ciliary neuron cell bodies or in the preganglionic terminals in the ganglion (Fig. $3 a$ ). Instead, the TH-IR of the ciliary neurons appeared increased; more ciliary ganglion neurons were detectably $\mathrm{TH}$ IR and the intensity of the TH-IR appeared greater. When adult rats were treated with 6-hydroxydopamine for $3 \mathrm{~d}$ and their ciliary ganglia examined on the fourth, there was no detectable difference in TH-IR in the ciliary neurons or in their preganglionic innervation. In sum, these observations suggest that both the postganglionic ciliary neurons and their preganglionic innervation lack a high-affinity catecholamine uptake system but do not exclude the possibility that this property is expressed at a low level.

Axons of the ciliary ganglion neurons in the iris also exhibited TH-IR. As reported by Bjorklund et al. (1985), the number of TH-IR fibers in the iris and the intensity of the immunoreactivity are dependent upon experimental conditions. In the irises of normal adults rats, a plexus of varicose and intensely $\mathrm{TH}$ -
IR sympathetic fibers was obvious (Fig. $6, a, b$ ). Since sympathetic and parasympathetic fibers course together over the entire iris (Ehinger and Falck, 1966; Ehinger et al., 1970b), the brightly immunofluorescent fibers might have obscured a second population of less intensely immunofluorescent fibers. Indeed, $2 \mathrm{~d}$ after the ipsilateral superior cervical ganglion was removed, the brightly immunofluorescent fibers had disappeared and a second, sparse plexus of smooth and faintly TH-IR fibers was revealed (Fig. 6, $c, d$ ). These fibers, just discernible in whole-mount preparations, were clearly evident in $10 \mu \mathrm{m}$ cryostat sections cut tangentially through perfusion-fixed irises (Fig. $6 d$ ). In the irises of adult rats sympathectomized at birth by repeated injections of 6-hydroxydopamine, a dense plexus of smooth, moderately immunofluorescent fibers was present (Fig. $6 e$ ). No THIR fibers were detectable in the irises of sympathectomized rats after the removal of the ipsilateral ciliary ganglion (Fig. 6f), indicating that the weakly TH-IR fibers arose in the ciliary ganglion.

In contrast to the ciliary ganglion, TH-IR was not detected in either the cholinergic neurons or preganglionic fibers of 2 other parasympathetic ganglia, the submandibular and the cardiac, nor in motoneurons in the spinal cord (data not shown). However, a small proportion of TH-IR neurons were evident in the sphenopalatine ganglion of adult rats (Leblanc and Landis, 1985). Most experiments utilized a TH antiserum made and characterized by one of us (J.T.). In addition, sections were stained with a second, commercially available $\mathrm{TH}$ antiserum raised against bovine adrenomedullary $\mathrm{TH}$ isolated by a different procedure (Joh and Ross, 1983) and with a mouse monoclonal antibody generated against TH purified from rat pheochromocytoma cells (Rohrer et al., 1986). The second antiserum and the mouse monoclonal antibody (Fig. 7) yielded staining of both ciliary neuron perikarya and preganglionic terminals similar to but less intense than that observed with the antiserum generated against rat $\mathrm{TH}$.

To ensure that our findings were not peculiar to albino rats, we examined $\mathrm{TH}$ staining and catecholamine histofluorescence in Long-Evans hooded rats and several other laboratory mammals. As in albino rats, many neurons and most preganglionic terminals in ciliary ganglia of hooded rats contained TH-IR (Fig. $8 a$ ). Similarly, the preganglionic terminals but not the postganglionic neurons, exhibited catecholamine fluorescence. In guinea pig (Fig. 8b), ferret (Fig. 8c), and mouse (Fig. 8d), the postganglionic neurons contained TH-IR; however, the preganglionic terminals in these animals lacked both TH-IR and catecholamine histofluorescence (Fig. 8e).

\section{Discussion}

We have found that many ciliary neurons in the normal adult rat, despite their cholinergic function, exhibit certain properties characteristic of catecholaminergic neurons: even though virtually all ciliary neurons exhibit ChAT-IR, many ganglion cells also possess TH-IR, some possess DBH-IR, and a small proportion exhibit both TH-IR and DBH-IR. In the case of TH, immunoreactivity has been detected in rat ciliary neurons using 2 antisera and a mouse monoclonal antibody generated against TH obtained with different purification methods and has not been observed in a majority of the other cholinergic neurons examined. These observations make it extremely likely, although they do not prove, that the immunoreactivity reflects the presence of authentic TH. From our immunocytochemical studies, it is not possible to determine whether the TH present 

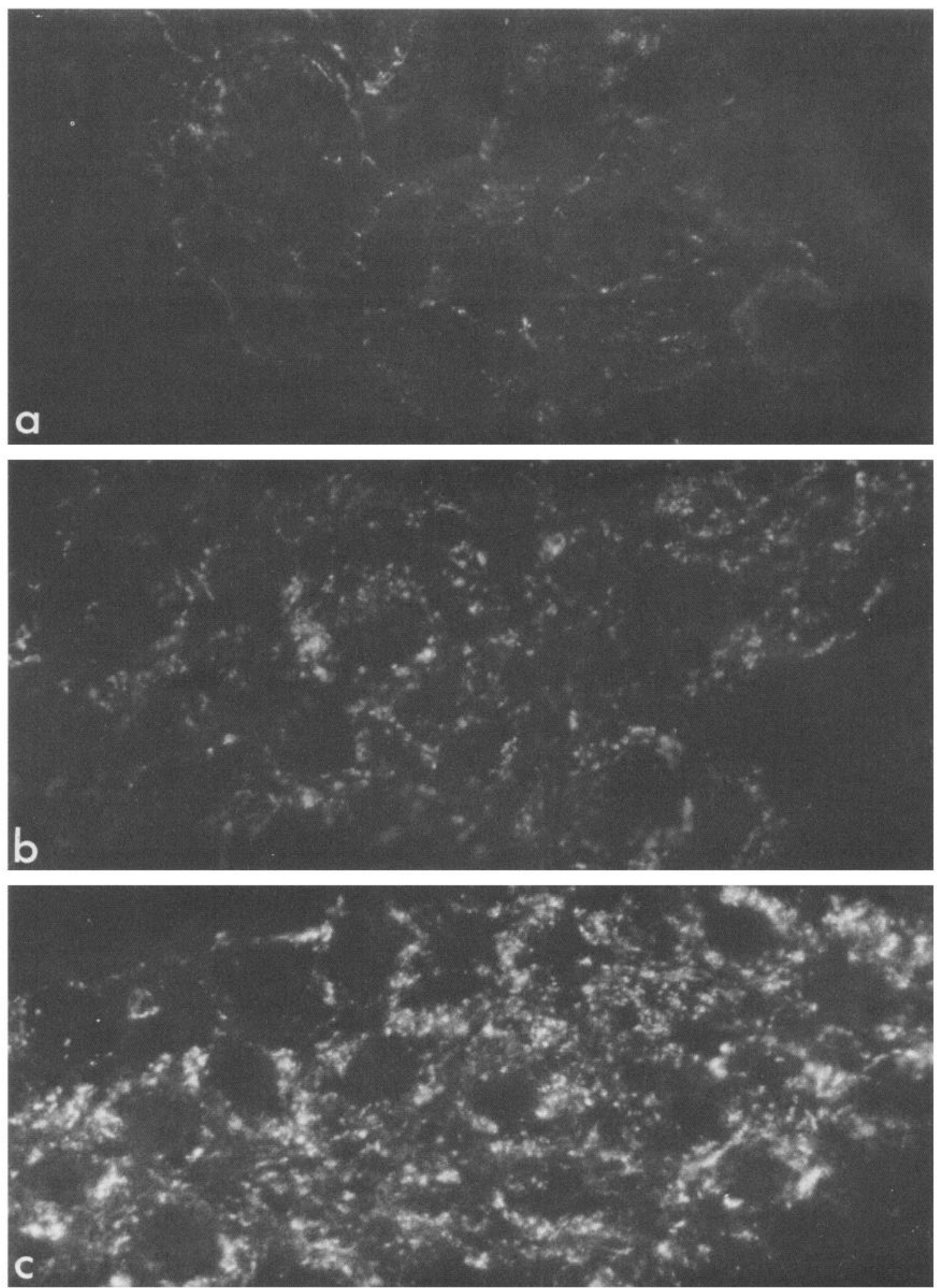

Figure 5. a, Light micrograph of an adult rat ciliary ganglion prepared for catecholamine histofluorescence by a glyoxylic acid method. Fluorescent terminals form a calyx around many cell bodies in the ganglion. No endogenous catecholamine fluorescence is evident in the cell bodies. $\times 450$. $b$, Light micrograph of the ciliary ganglion of an adult rat treated with nialamide prior to preparation for catecholamine histofluorescence by a glyoxylic acid method. The intensity of the catecholamine histofluorescence in the presynaptic terminals is significantly increased, but no fluorescence is detectable in the principal ciliary neurons. $\times 450 . c$, Light micrograph of the ciliary ganglion of an adult rat treated with L-DOPA and nialamide prinr to preparation for catecholamine histofluorescence by a glyoxylic acid method. Treatment with nialamide and L-DOPA results in even greater catecholamine histofluorescence in the preganglionic terminals but still does not yield detectable catecholamine fluorescence in the principal neurons. $\times 450$. 

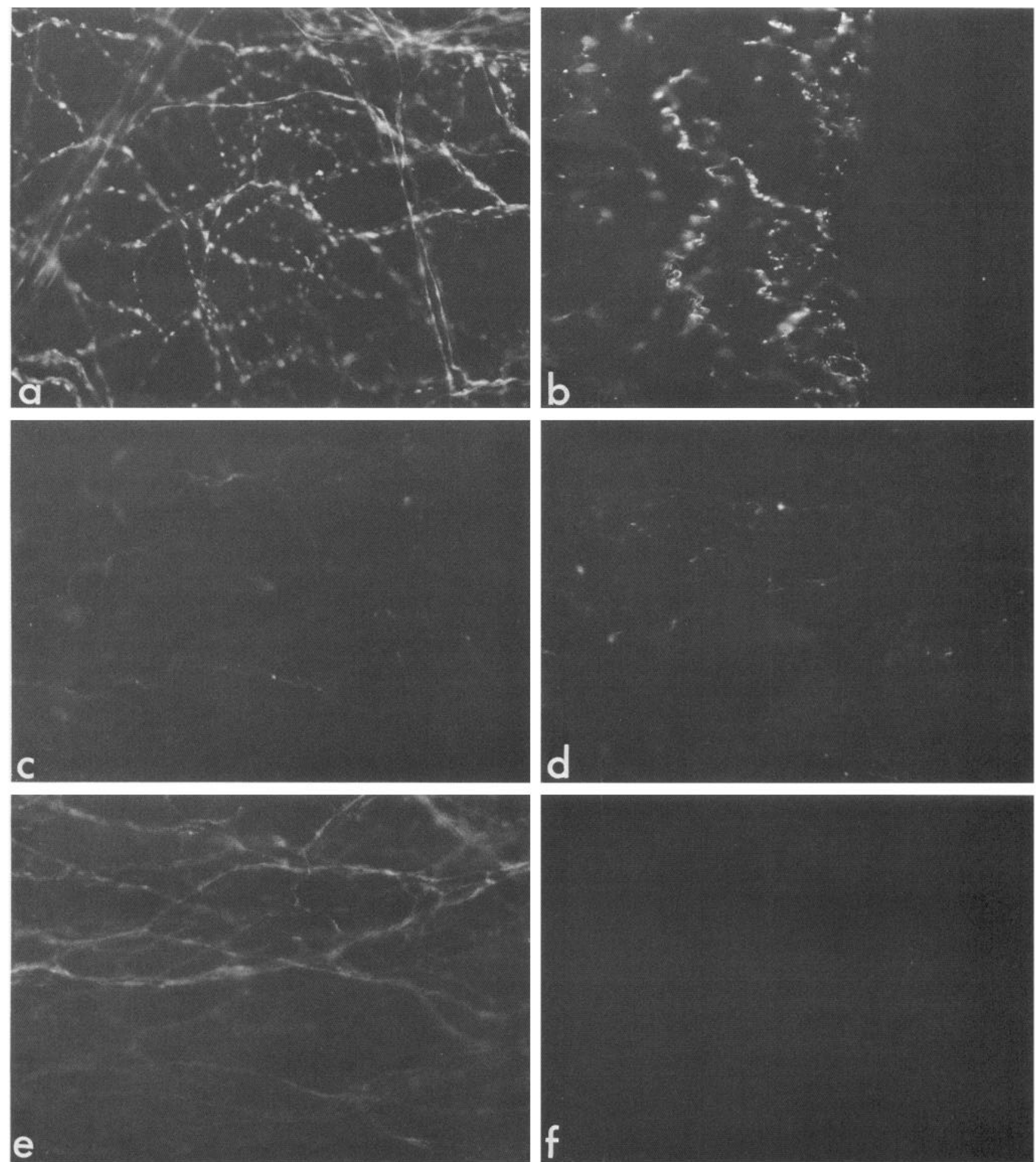

Figure 6. $a$, Light micrograph of an iris stretch preparation of a normal adult rat labeled with TH antiserum. A dense plexus of intensely immunoreactive, varicose sympathetic fibers is evident in the dilator. $\times 450 . b$, Light micrograph of an iris from a normal adult rat labeled with $\mathrm{TH}$ antiserum. Intensely immunoreactive varicose sympathetic fibers are evident in $10 \mu \mathrm{m}$ sections cut tangential to the plane of the autonomic plexus in the dilator. $\times 450$. $c$, Light micrograph of an iris stretch preparation of an adult rat whose superior cervical ganglion had been removed $2 \mathrm{~d}$ prior to examination. A sparse plexus of smooth and weakly TH-IR fibers is evident in the dilator. When irides from such animals were stained with $\mathrm{AChE}$ or for the presence of synaptic vesicle antigen to reveal the parasympathetic plexus, a dense meshwork of fibers was evident in the dilator region. $\times 450 . d$, Light micrograph of an iris from an adult rat whose superior cervical ganglion had been removed $2 \mathrm{~d}$ prior to examination. Occasional smooth and weakly immunoreactive fibers are present in $10 \mu \mathrm{m}$ sections cut tangential to the plane of the autonomic plexus in the dilator. $\times 450$. $e$, Light micrograph of an iris stretch preparation of an adult rat sympathectomized at birth by multiple treatments with 6 -hydroxydopamine. A dense plexus of smooth and moderately immunofluorescent fibers is present in the dilator. $\times 450 . f$, Light micrograph of an iris stretch preparation of an adult rat sympathectomized at birth with 6-hydroxydopamine. Four days prior to examination, the ciliary ganglion was removed surgically. No TH-IR fibers are evident in the iris. $\times 450$. 


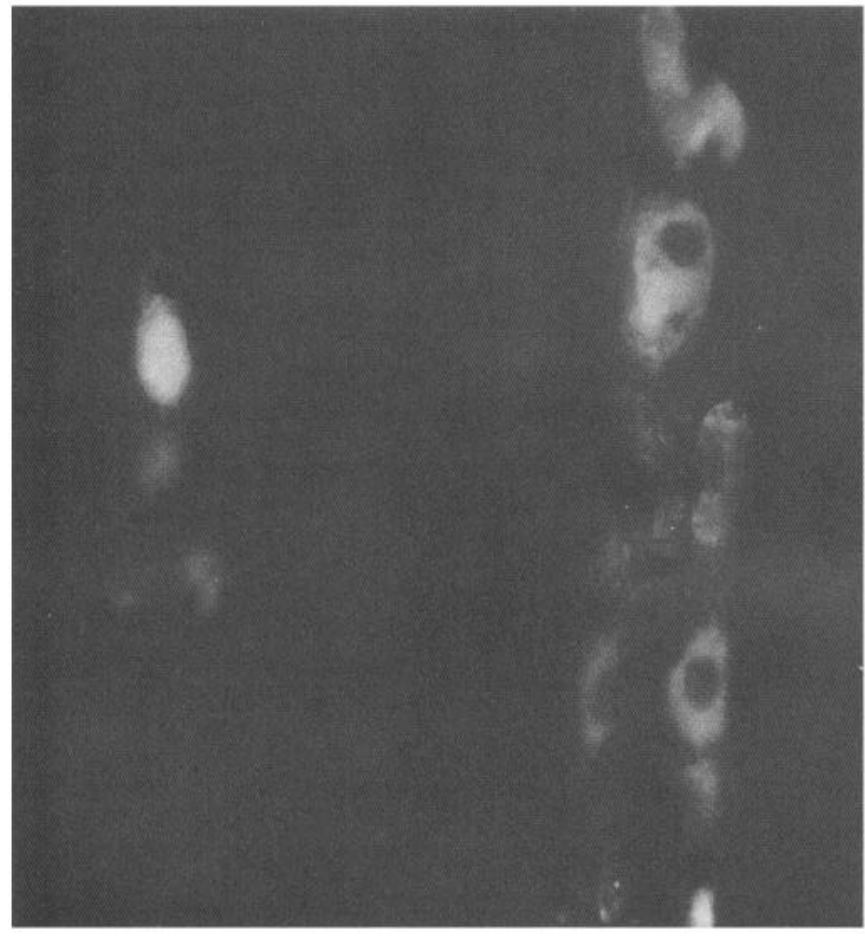

Figure 7. Light micrograph of an adult rat ciliary ganglion labeled with a mouse monoclonal antibody that recognizes TH. Several immunoreactive principal neurons are evident. $\times 325$.

in the postganglionic ciliary neurons was catalytically active. In preliminary studies, TH activity was assayed by examining DOPA accumulation in the presence of brocresine, a DOPA decarboxylase inhibitor, by high-performance liquid chromatography (Ip et al., 1982). Since each rat ciliary ganglion contains only 125 neurons, of which at most 40 display TH-IR of varying intensity, 3 ganglia were pooled for each assay. In 3 experiments, a low but reproducible level of TH activity was observed, on average $230 \mathrm{fmol}$ DOPA were formed per ganglion per hr. Since the preganglionic terminals as well as postganglionic neurons contain TH-IR, it is not possible to assign catalytic activity to the postganglionic neurons without additional studies using rats whose preganglionic input had been surgically removed. Our finding that no catecholamine fluorescence could be detected in the postganglionic neurons even after treatment with the monoamine oxidase inhibitor nialamide and exogenous DOPA indicates that these neurons lack the enzyme L-aromatic acid decarboxylase (DOPA decarboxylase), which converts DOPA to dopamine. Given that the neurons cannot convert DOPA to dopamine, the issue of whether the TH present in them is catalytically active becomes of questionable functional significance. Although L-aromatic acid decarboxylase is widely distributed in non-neuronal peripheral tissues, in the mammalian CNS it is largely, although not exclusively, restricted to neurons that use monoamines as neurotransmitters (Hökfelt et al., 1973; Jaeger et al., 1983, 1984). In addition, ciliary neurons and their terminals in the iris lack the ability to accumulate detectable stores of exogenous catecholamine (see also Landis and Keefe, 1983).

Despite the presence of TH-IR in up to $40 \%$ of postganglionic ciliary neuron perikarya, very few parasympathetic axons in the irises of normal adult rats contained detectable levels of TH-
IR. In contrast, the terminals of sympathetic neurons, exhibiting TH-IR indistinguishable from that present in at least some of the ciliary neurons, were intensely immunoreactive. A similar discrepancy exists between the expression of neuropeptide Y-like (NPY-IR) immunoreactivity in the cell bodies (Leblanc and Landis, 1987) and terminals of ciliary neurons (Bjorklund et al., 1985). These observations suggest that neither transmitter synthetic enzymes nor neuropeptides need be uniformly distributed throughout the neuron. Thus, the presence of immunoreactivity in neuronal perikarya does not necessarily mean that it will be present in the terminal plexus. As reported by Bjorklund and colleagues (1985), we have found that a dense plexus of moderately TH-IR fibers appears in the irises of chronically sympathectomized rats. Bjorklund suggests that mature cholinergic neurons in vivo are capable of expressing adrenergic properties under experimental conditions due either to the induction of a new transmitter phenotype or to the increased expression of properties previously undetectable by immunocytochemical assay. Our examination of TH-IR in sections of ciliary ganglia revealed that many ciliary neuronal perikarya normally contain TH-IR and indicate that the effect of chronic sympathectomy is to increase the levels of TH-IR in individual neurons rather than to cause the induction of a new phenotypic property. Since the effect of sympathectomy on TH-IR in axon terminals was more striking than on the TH-IR in the neuronal cell bodies, it also seems likely that sympathectomy increases the transport of TH-IR into the axonal plexus. A reasonable candidate for mediating these effects is NGF (see also Bjorklund et al., 1985). Denervation results in increased NGF levels in the iris (Ebendal et al. 1980; Barth et al., 1983), and NGF is known to regulate levels of $\mathrm{TH}$ in both developing and mature sympathetic neurons (Thoenen et al., 1971; Black et al., 1972; Chun and Patterson, 1977; Otten et al., 1977; Goedert et al., 1978; Thoenen and Barde, 1980). Although ciliary neurons are not dependent upon NGF for survival (Pearson et al., 1983), they possess NGF receptors and can retrogradely transport NGF (Max et al., 1978). Ciliary neurons are also NGF-responsive. In culture, NGF increases neurite extension (Collins, 1984). In vivo treatment with exogenous NGF causes increased ChAT activity in the iris (Kessler, 1985). Finally, sympathectomy increases ChAT activity, and this effect can be blocked by injection of NGF antiserum into the anterior chamber (Kessler, 1985).

The expression of particular catecholaminergic properties by several classes of nonsympathetic and putatively nonadrenergic peripheral neurons has been reported in adult animals previously: parasympathetic submandibular ganglion neurons have DBH enzyme activity and immunoreactivity (Coyle et al., 1974; Grzanna and Coyle, 1978), and nodose, petrosal, and dorsal root sensory ganglion cells have TH-IR and catecholamine fluorescence detectable after monoamine oxidase inhibition (Katz et al., 1983; Price and Mudge, 1983). In addition, during embryonic or postnatal development, neurons that are not destined to be functionally catecholaminergic in the adult may express certain properties characteristic of the catecholaminergic phenotype transiently (Cochard et al., 1979; Teitelman et al., 1979; Jonakait et al., 1979, 1984, 1985; Jaeger and Joh, 1983; Gershon et al., 1984; Berger et al., 1985). Most recently, Teitelman and Iacovitti have found that a small proportion of embryonic chick ciliary neurons in vivo and a large proportion in vitro express TH-IR (Iacovitti et al., 1985; Teitelman et al., 1985). The functional consequences of these catecholaminergic properties are unclear. 


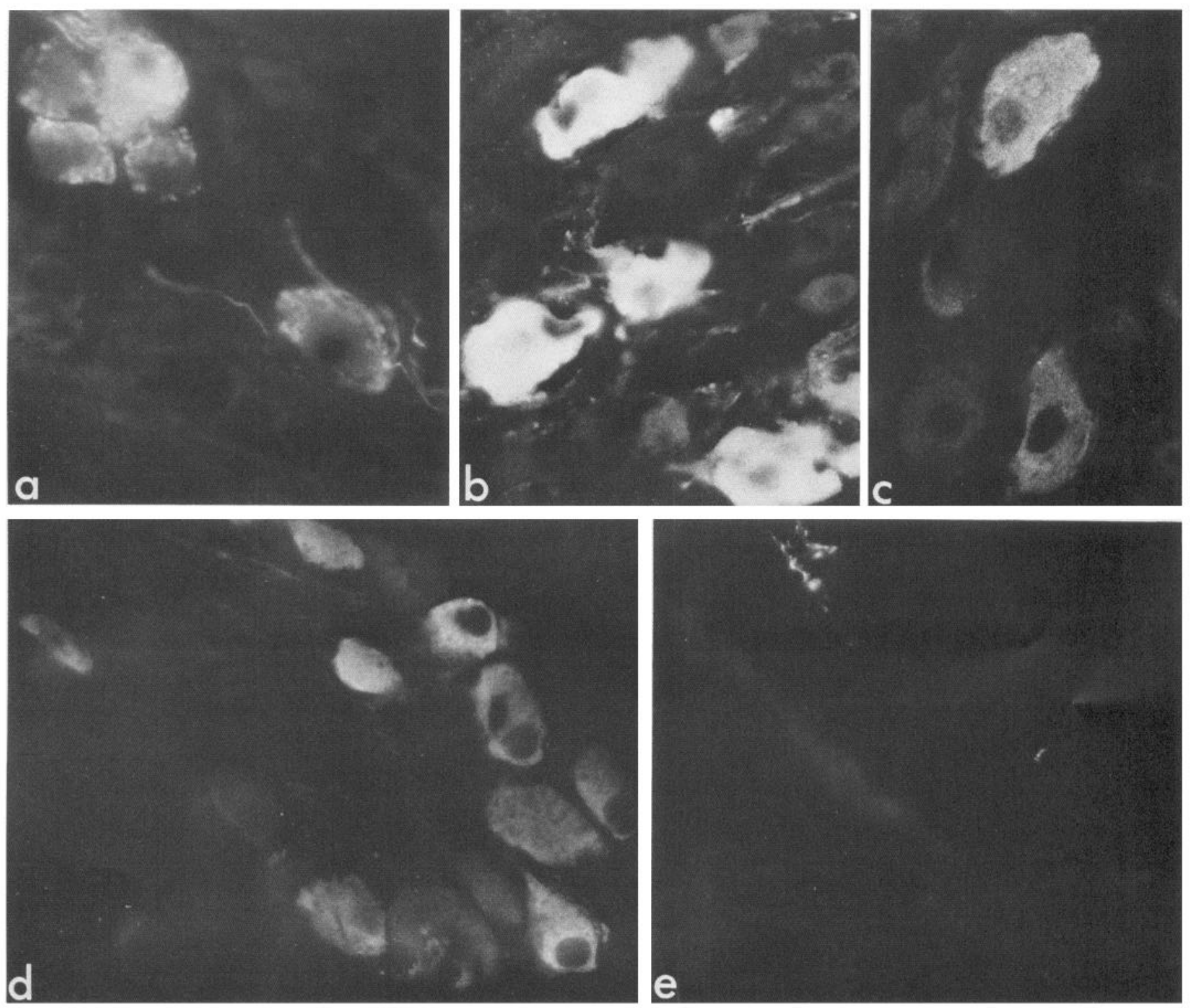

Figure 8. $a$, Light micrograph of the ciliary ganglion of a normal adult Long-Evans hooded rat labeled with TH antiserum. Both neuronal perikarya and preganglionic terminals are immunofluorescent. $\times 480 . b$, Light micrograph of the ciliary ganglion of a normal adult guinea pig labeled with $\mathrm{TH}$ antiserum. Numerous neuronal perikarya are immunoreactive but the preganglionic terminals lack detectable $\mathrm{TH}$ immunoreactivity. $\times 450$. $c$, Light micrograph of the ciliary ganglion of an adult ferret labeled with TH antiserum. Some neuronal perikarya but no preganglionic fibers are immunoreactive. $\times 450$. $d$, Light micrograph of the ciliary ganglion of an adult mouse labeled with TH antiserum. TH immunoreactivity is evident in numerous principal neurons, but no TH labeling is detectable in presynaptic terminals surrounding neuronal perikarya. $\times 450 . e$, Light micrograph of the ciliary ganglion of an adult mouse prepared for catecholamine histofluorescence by a glyoxlic acid method. No catecholamine histofluorescence is evident in either the ciliary neurons or preganglionic terminals within the ganglion. Noradrenergic sympathetic fibers are seen innervating a blood vessel in the upper left corner. $\times 450$.

We also observed TH-IR and catecholamine histofluorescence in preganglionic terminals in the ciliary ganglion. In the case of the preganglionic fibers, the presence of detectable endogenous catecholamine stores in the absence of detectable accumulation of exogenous catecholamine indicates that the THIR reflects actual TH enzyme activity and that L-aromatic acid decarboxylase is present. The presence of catecholamine-containing fibers surrounding neurons in the rat ciliary ganglion has been described previously by Huikuri (1966), who noted that dopamine-containing neurons were present in the region of the Edinger-Westphal nucleus (Dahlstrom and Fuxe, 1965) where the cell bodies of the preganglionic neurons are located (War- wick, 1954; Loewy et al., 1978; Johnson and Purves, 1981). In subsequent studies, Ehinger reported the presence in ciliary ganglia of terminals containing very low levels of endogenous catecholamine that could synthesize catecholamine from DOPA and accumulate exogenous catecholamine (Ehinger and Falck, 1970). $\mathrm{He}$ suggested that these terminals were intraganglionic in origin. Our studies confirm the presence of significant stores of catecholamine and demonstrate its location in preganglionic terminals. Since neither DBH-IR nor small granular vesicles following permanganate fixation were evident in these terminals, it is likely that the catecholamine stored is dopamine. The preganglionic terminals exhibited immunoreactivity for choline 
acetyltransferase, and preliminary physiological studies indicate that, as in the cat (Langley and Anderson, 1892; Perry and Talesnik, 1953), synaptic transmission in the rat ciliary ganglion is blocked by cholinergic antagonists (Jackson, unpublished observations). Thus, in the adult rat ciliary ganglion, the preganglionic terminals appear to contain not only $\mathrm{ACh}$, which effects neurotransmission, but also a catecholamine whose functional role at the synapse is as yet uncharacterized. Varicose catecholamine-containing fibers have also been observed in the avian ciliary ganglion (Ehinger, 1967). However, in contrast to rat, these appear to be sympathetic in origin and do not form synaptic specializations (Cantino and Mugnaini, 1974). The preganglionic terminals in the several other mammalian species examined in the present study, like those of the chick, lacked detectable TH-IR and catccholamine histofluorescence.

To date, the coexistence and co-release of $\mathrm{ACh}$ and a catecholamine have been directly demonstrated only for dissociated rat sympathetic neurons developing on heart cells in microculture (Furshpan et al., 1976; Potter et al., 1986). Coexistence of ACh and peptides has been previously reported for preganglionic parasympathetic neurons in avian (Erichsen et al., 1982) and cat ciliary ganglia (Kondo el al., 1982) and for preganglionic sympathetic neurons in frog sympathetic ganglia (Jan et al., 1980). The present observation of dopamine in the functionally cholinergic preganglionic terminals in the rat ciliary ganglion, however, appears to provide the first example of the coexistence of ACh and a catecholamine in mature neurons in vivo and thus extends the existing range of transmitter colocalization and possible multiple function in neurons.

The developmental mechanisms responsible for the induction and maintenance of catecholaminergic properties in ciliary neurons and their preganglionic innervation are as yet undefined. Sympathetic neurons and adrenal medullary cells, the functionally adrenergic derivatives of the neural crest, arise from trunk crest (reviewed in LeDouarin, 1983). Analysis of chick-quail chimeras suggests that neural crest cells are induced to become adrenergic during migration or at the cessation of migration by interactions with the local environment (e.g., LeDouarin and Teillet, 1974; LeDouarin et al., 1975), although adrenergic properties such as TH-IR and catecholamine histofluorescence are not expressed until after migration is complete and the crest cells have begun to aggregate to form ganglia (Cochard et al., 1979; Teitelman et al., 1979). Transplantation and cell culture experiments implicate a complex of tissues, including the neural tube, notochord, and somitic mesenchyme, in this induction in vivo, although the contributions of the individual tissues and the active factors remain to be identified (e.g., Cohen, 1972; Norr, 1973; Teillet et al., 1978; Howard and Bronner-Fraser, 1985). Ciliary ganglion neurons are derived from mesencephalic neural crest (Narayanan and Narayanan, 1978; Noden, 1978; LeDouarin, 1983). The migratory pathway of mesencephalic crest cells is significantly different from that of trunk crest; the mesencephalic crest is the only region in the avian embryo where crest cells do not migrate ventrally along the ncural tube (Noden, 1978; Duband and Thiery, 1982; Tosney, 1982). Mesencephalic crest cells are competent to respond to adrenergic inducing signals present in the trunk region; premigratory cranial neural crest cells, the non-neuronal cells in embryonic ciliary ganglia, and some ciliary ganglion neurons give rise to catecholaminecontaining sympathetic neurons and adrenal medullary cells when transplanted to the trunk region (LeDouarin and Teillet, 1974; Dupin, 1984; Coulombe and Bronner-Fraser, 1986). Sim- ilarly, the proportion of TH-IR neurons present in dissociated cell cultures of embryonic chick ciliary ganglion can be significantly increased by coculture with notochord (Teitelman et al., 1985). It is possible that some, as yet to be defined, combination of tissues in the head is capable of inducing a partial catecholaminergic phenotype, which may be transiently expressed as in the case of the cranial sensory neurons (Jonakait et al., 1984) or permanently as in the case of many ciliary neurons. The preganglionic neurons arise from the ventricular zone in the neural tube. In contrast to the neural crest, very little is known about the mechanisms regulating transmitter determination for neurons in the neural tube. The finding that in the rat, but not several other laboratory species, $\mathrm{ACh}$ and a catecholamine coexist in the parasympathetic preganglionic neurons innervating the ciliary ganglion indicates that some flexibility exists in that the developmental mechanisms which generally result in the segregation of these 2 transmitter phenotypes in the CNS.

\section{References}

Barth, E. M., S. Korsching, and H. Thoenen (1983) Regulation of nerve growth factor synthesis and release in organ cultures of rat iris. J. Cell Biol. 99: 839-843.

Berger, B., C. Verney, P. Gaspar, and A. Febvret (1985) Transient expression of tyrosine hydroxylase immunoreactivity in some neurons of the rat neocortex during postnatal development. Brain Res. 23: 141-144.

Bjorklund, H., T. Hökfelt, M. Goldstein, L. Terenius, and L. Olson (1985) Appearance of the noradrenergic markers tyrosine hydroxylase and neuropeptide $\mathrm{Y}$ in cholinergic nerves of the iris following sympathectomy. J. Neurosci. 5: 1633-1643.

Black, I. B., I. A. Hendry, and L. L. Iversen (1972) Effects of surgical decentralization and nerve growth factor on the maturation of adrenergic neurons in a mouse sympathetic ganglion. J. Neurochem. 19. $1367-1377$

Buckley, G., A. Consolo, E. Giacobini, and R. McCaman (1967) A micromethod for the determination of choline acctylase in individual cells. Acta Physiol. Scand. 71: 341-347.

Cantino, D., and E. Mugnaini (1974) Adrenergic innervation of the parasympathetic ciliary ganglia in the chick. Science 185: 279-281.

Chun, L. L. Y., and P. H. Patterson (1977) The role of nerve growth factor in development of sympathetic neurons in vitro. I. Survival, growth and differentiation of catecholamine production. J. Cell Biol. 75: 694-704.

Clark, D. W., R. Laverty, and E. L. Phelan (1972) Long-lasting peripheral and central effects of 6-hydroxydopamine in rats. Br. J. Pharmacol. 44: 233-243.

Cochard, P., M. Goldstein, and I. B. Black (1979) Initial development of the noradrenergic phenotype in autonomic neuroblasts of the rat embryo in vivo. Dev. Biol. 71: 100-114.

Cohen, A. M. (1972) Factors dirceting the expression of sympathetic nerve traits in cells of neural crest origin. J. Exp. Zool. 179: 167-182.

Collins, F. (1984) An effect of nerve growth factor on the parasympathetic ciliary ganglion. J. Neurosci. 4: 1281-1288.

Coulombe, J. N., and M. Bronner-Fraser (1986) Cholinergic neurones acquire adrenergic neurotransmitters when transplanted into an embryo. Nature 324: 569-572.

Coyle, J. T., G. F. Wooten, and J. Axelrod (1974) Evidence for extranoradrenergic dopamine- $\beta$-hydroxylase activity in rat salivary gland. J. Neurochem. 22: 923-929.

Dahlstrom, A., and K. Fuxe (1965) Evidence for the existence of monoamine neurons in the central nervous system. Acta Physiol. Scand. Suppl. 247: 1-85.

de la Torre, J. C. (1980) An improved approach to histofluorescence using the SPG method for tissuc monamincs. J. Ncurosci. Methods 3: $1-5$.

Duband, J. L., and J. P. Thiery (1982) Distribution of fibronectin in the early phase of avian cephalic neural crest cell migration. Dev. Biol. 93: 308-323.

Dupin, E. (1984) Cell division in the ciliary ganglion of quail embryos in situ and after back-transplantation into the neural crest migration pathways of chick embryos. Dev. Biol. 105: 288-299. 
Ebendal, T., L. Olson, A. Seiger, and K. O. Hedlund (1980) Nerve growth factors in the iris. Nature 286: 25-28.

Eckenstein, F., Y.-A. Barde, and H. Thoenen (1981) Production of specific antibodics to choline acetyltransfcrasc purificd from pig brain. Neuroscience 6: 993-1000.

Ehinger, B. (1967) Adrenergic nerves in the avian eye and ciliary ganglion. Z. Zellforschung. 82: 577-588.

Ehinger, B., and B. Falck (1966) Concomitant adrenergic and parasympathetic fibres in the rat iris. Acta Physiol. Scand. 67: 201-207.

Ehinger, B., and B. Falck (1970) Uptake of some catecholamines and their precursors into neurons of the rat ciliary ganglion. Acta Physiol. Scand. 78: 132-141.

Ehinger, B., B. Falck, H. Persson, A. M. Rosengren, and E. Rosengren (1966) Choline acetylase activity in the normal and denervated cat iris. Life Sci. 5: 481-483.

Ehinger, B., B. Falck, and H. Persson (1968) Function of cholinergic nerve fibres in the cat iris dilator. Acta Physiol. Scand. 72: 139-147.

Ehinger, B., B. Falck, H. Persson, A. M. Rosengren, and B. Sporrong (1970a) Acetylcholine in adrenergic terminals of the cat iris. J. Physiol. (Lond.) 209: 557-565.

Ehinger, B., B. Falck, and B. Sporrong (1970b) Possible axo-axonal synapses between peripheral adrenergic and cholinergic nerve terminals. Z. Zellforsch. 107: 508-521.

Erichsen, J. T., H. J. Karten, W. D. Eldred, and N. C. Brecha (1982) Localization of substance P-like and enkephalin-like immunoreactivity within preganglionic terminals of the avian ciliary ganglion: Light and electron microscopy. J. Neurosci. 2: 994-1003.

Finch, L., G. Haeusler, and H. Thoenen (1973) A comparison of the effects of chemical sympathectomy by 6-hydroxydopamine in newborn and adult rats. Br. J. Pharmacol. 47: 249-260.

Furshpan, E. J., P. R. MacLeish, P. O'Lague, and D. D. Potter (1976) Chemical transmission between rat sympathetic neurons and cardiac myocytes developing in microcultures: Evidence for cholinergic, adrenergic and dual function neurons. Proc. Natl. Acad. Sci. USA 73: $4225-4229$.

Gershon, M. D., T. P. Rothman, T. H. Joh, and G. N. Teitelman (1984) Transient and differential expression of aspects of the catecholaminergic phenotype during development of the fetal bowel of rats and mice. J. Neurosci. 4: 2269-2280.

Goedert, M., U. Otten, and H. Thoenen (1978) Biochemical effects of antibodies against Nerve Growth Factor on developing and differentiated sympathetic ganglia. Brain Res. 148: 264-268.

Grzanna, R., and J. T. Coyle (1978) Dopamine- $\beta$-hydroxylase in rat submandibular ganglion cells which lack norepinephrine. Brain Res. 151: 206-214.

Grzanna, R., M. E. Molliver, and J. T. Coyle (1976) Rat adrenal dopamine- $\beta$-hydroxylase: Purification and immunologic characteristics. J. Neurochem. 27: 1091-1096.

Hendry, I. A., L. L. Iversen, and I. B. Black (1973) A comparison of the neural regulation of tyrosine hydroxylase activity in sympathetic ganglia of adult mice and rats. J. Neurochem. 20: 1683-1689.

Higgins, D., L. Iacovitti, T. H. Joh, and H. Burton (1981) The immunocytochemical localization of tyrosine hydroxylase within rat sympathetic neurons that release acetylcholine in culture. J. Neurosci. I: $126-131$.

Hökfelt, T. (1968) In vitro studies on central and peripheral monoamine neurons at the ultrastructural level. Z. Zellforsch. 91: 1-74.

Hökfelt, T., and G. Jonsson (1968) Studies on reaction and binding of monoamines after fixation and processing for electron microscopy with special reference to fixation with potassium permanganate. Histochemie 16: 45-67.

Hökfelt, T., K. Fuxe, and M. Goldstein (1973) Immunohistochemical localization of aromatic L-amino acid decarboxylase (DOPA decarboxylase) in central dopamine and 5-hydroxytryptamine nerve cell bodies of the rat. Brain Res. 53: 175-180.

Howard, M. J., and M. Bronner-Fraser (1985) The influence of neural tube-derived factors on the differentiation of neural crest cells in vitro. I. Histochemical study on the appearance of adrenergic cells. J. Neurosci. 5: 3302-3309.

Huikuri, K. T. (1966) Histochemistry of the ciliary ganglion of the rat and the effect of pre- and postganglionic nerve division. Acta Physiol. Scand. Suppl. 286: 69

Iacovitti, L., T. H. Joh, D. H. Park, and R. P. Bunge (1981) Dual expression of neurotransmitter synthesis in cultured neurons. J. Neurosci. 1: 685-690.
Iacovitti, L., T. H. Joh, V. R. Albert, D. H. Park, D. J. Reis, and G. Teitelman (1985) Partial expression of catecholaminergic traits in cholinergic chick ciliary ganglia: Studies in vivo and in vitro. Dev. Biol. 110: 402-412.

Ip, N. Y., R. L. Pearlman, and R. E. Zigmond (1982) Both nicotinic and muscarinic agonists increase tyrosine 3 -monooxygenase activity in the superior cervical ganglion. J. Pharmacol. Exp. Ther. 223: 280283.

Jackson, P. C. (1986) Innervation of the iris by individual parasympathetic axons in the adult mouse. J. Physiol. (Lond.) 378: 485-495.

Jaeger, C. B., and T. H. Joh (1983) Transient expression of tyrosine hydroxylase in some neurons of the developing inferior colliculus. Dev. Brain Res. 11: 128-132.

Jaeger, C. B., G. Teitelman, T. H. Joh, V. R. Albert, T. H. Park, and D. J. Reis (1983) Some neurons of the rat central nervous system contain aromatic $\mathrm{L}$ amino acid decarboxylase but not monoamines. Science 219: 1233-1235.

Jaeger, C. B., D. Z. Ruggiero, V. R. Albert, D. H. Park, T. H. Joh, and D. J. Reis (1984) Aromatic L-amino acid decarboxylase in the rat brain: Immunocytochemical localization in neurons of the brain stem. J. Neurosci. 4: 691-714.

Jan, L. Y., Y. N. Jan, and M. S. Brownfield (1980) Peptidergic transmitters in synaptic boutons of sympathetic ganglia. Nature 288:380383.

Joh, T. H., and M. E. Ross (1983) Preparation of catecholamine synthetic enzymes as immunogens for immunocytochemistry. In $1 \mathrm{~m}$ munohistochemistry. IBRO Handbook Series: Methods in the Neurosciences, Vol. 3, A. C. Cuello, ed., pp. 121-138, Wiley, Chichester, England.

Johnson, D. A., and D. J. Purves (1981) Postnatal reduction on neural unit size in the rabbit ciliary ganglion. J. Physiol. (Lond.) 318: 143159.

Johnson, M., D. Ross, M. Meyers, R. Bunge, E. Wakshull, and H. Burton (1976) Synaptic vesicle cytochemistry changes when cultured sympathelic neurons develop cholinergic interactions. Nature 262: 308310 .

Johnson, M., C. D. Ross, M. Meyers, R. Rees, E. L. Spitznagel, and R. P. Bunge (1980) Morphological and biochemical studies on the development of cholinergic properties in cultured sympathetic neurons. I. Correlative changes in choline acetyltransferase and synaptic vesicle cytochemistry. J. Cell Biol. 84: 680-691.

Jonakait, G. M., J. Wolf, P. Cochard, M. Goldstein, and I. B. Black (1979) Selective loss of noradrenergic phenotypic characteristics in neuroblasts of the rat embryo. Proc. Natl. Acad. Sci. USA 76: 46834686.

Jonakait, G. M., K. A. Markey, M. Goldstein, and I. B. Black (1984) Transient expression of selected catecholaminergic traits in cranial sensory and dorsal root ganglia of the embryonic rat. Dev. Biol. 101 : $51-60$.

Jonakait, G. M., K. A. Markey, M. Goldstein, C. F. Dreyfus, and I. B. Black (1985) Selective expression of high affinity uptake of catecholamines by transiently catecholaminergic cells of the rat embryo: Studies in vivo and in vitro. Dev. Biol. 108: 6-17.

Katz, D. M., K. A. Markey, M. Goldstein, and I. B. Black (1983) Expression of catecholaminergic characteristics by primary sensory neurons in the normal adult rat in vivo. Proc. Natl. Acad. Sci. USA 80: 3526-3530.

Kessler, J. A. (1985) Parasympathetic, sympathetic and sensory interactions in the iris: Nerve growth factor regulates cholinergic ciliary ganglion innervation in vivo. J. Neurosci. 5: 2719-2725.

Kondo, K., Y. Katayama, and R. Yui (1982) On the occurrence and physiological effect of somatostatin in the ciliary ganglion of cats. Brain Res. 247: 141-144.

Landis, S. C. (1976) Rat sympathetic neurons and cardiac myocytes developing in microcultures: Correlation of the fine structure of endings with neurotransmitter function in singe neurons. Proc. Natl. Acad. Sci. USA 73: 4220-4224.

Landis, S. C. (1980) Developmental changes in the neurotransmitter properties of dissociated sympathetic neurons: A cytochemical study of effects of the medium. Dev. Biol. 77: 349-361.

Landis, S. C., and D. Keefe (1983) Evidence for neurotransmitter plasticity in vivo: Developmental changes in properties of cholinergic sympathetic neurons. Dev. Biol. 98: 349-372.

Landis, S. C., P. C. Jackson, and J. R. Fredieu (1983) Catecholaminergic properties of neurons and preganglionic axons in the rat ciliary 
ganglion. Soc. Neurosci. Abstr. 9: 274.9.

Langley, J. N. (1891) On the course and connections of secretory fibres supplying the sweat glands of the feet of the cat. J. Physiol. (Lond.) 12: 347-374.

Langley, J. N. (1922) The secretion of sweat. Part I. Supposed inhibitory nerve fibres on the posterior nerve of cats. Secretion after denervation. J. Physiol. (Lond.) 56: 110-119.

Langley, J. N., and H. K. Anderson (1892) The action of nicotine on the ciliary ganglion and on the endings of the third cranial nerve. J. Physiol. (Lond.) 13: 460-468.

Leblanc, G., and S. C. Landis (1985) Development of tyrosine hydroxylase immunoreactivity in neurons of the parasympathetic sphenopalatine ganglion in the rat. Soc. Neurosci. Abstr. 11: 200.2.

Leblanc, G., and S. C. Landis (1986) Development of choline acetyltransferase in the sympathetic innervation of rat sweat glands. J Neurosci. 6: 260-265.

Leblanc, G., and S. C. Landis (1987) Neuropeptide Y-like immunoreactivity in rat cranial parasympathetic neurons: Coexistence with vasoactive intestinal peptide and choline acetyltransferase. Proc. Natl Acad. Sci. USA 84: 3511-3515.

LeDouarin, N. (1983) The Neural Crest, Cambridge University Press, Cambridge, U.K

LeDouarin, N., and M. Teillet (1974) Experimental analysis of the migration of neuroblasts of the autonomic nervous system and of neuroectodermal derivatives using a biological cell marking technique. Dev. Biol. 41: 162-184.

LeDouarin, N. M., D. Renaud, M. A. Teillet, and G. H. LeDouarin (1975) Cholinergic differentiation of presumptive adrenergic neuroblasts in interspecific chimeras after heterotopic transplantation. Proc. Natl. Acad. Sci. USA 72: 728-732.

Loewy, A. D., C. B. Saper, and N. D. Yamodis (1978) Re-evaluation of the efferent projections of the Edinger-Westphal nucleus in the cat Brain Res. 141: 153-159.

Matthew, W. D., L. Tsavaler, and L. Reichardt (1981) Identification of a synaptic vesicle specific membrane protein with a wide distribution in neuronal and neurosecretory cells. J. Cell Biol. 91: 257269.

Max, S. R., M. Schwab, M. Dumas, and H. Thoenen (1978) Retrugrade axonal transport of nerve growth factor in the ciliary ganglion of the chick and the rat. Brain Res. 159: 41 1-415.

Narayanan, C. H., and Y. Narayanan (1978) On the origin of the ciliary ganglion in birds studied by the method of interspecific transplantation of embryonic brain regions between quail and chick. J. Embryol. Exp. Morphol. 47: 137-148.

Noden, D. (1978) The control of avian cephalic crest cytodifferentiation. II. Neural tissues. Dev. Biol. 67: 313-329.

Norr, S. C. (1973) In vitro analysis of sympathetic neuron differentiation from chick neural crest cells. Dev. Biol. 34: 16-38.

Ordronneau, P., P. Lindstrom, and P. Petrusz (1981) Four unlabelled antibody bridge techniques: A comparison. J. Histochem. Cytochem. 29: $1397-1404$

Otten, U., M. Schwab, C. Gagnon, and H. Thuenen (1977) Selective induction of tyrosine hydroxylase and dopamine- $\beta$-hydroxylase by Nerve Growth Factor: Comparison between adrenal medulla and sympathetic ganglia of adult and newborn rats. Brain Res. 133: 291303.

Patterson, P. H., and L. L. Y. Chun (1977) The induction of acetylcholine synthesis in primary cultures of dissociated rat sympathetic neurons: Il. Developmental aspects. Dev. Biol. 60: 473-481.

Pearson, J., E. M. Johnson, and L. Brandeis (1983) Effects of antibodies to nerve growth factor on intrauterine development of derivatives of cranial neural crest and placode in the guinea pig. Dev. Biol. 96: 32-36.

Perry, W. L. M., and J. Talesnik (1953) The role of acetylcholine in synaptic transmission at parasympathetic ganglia. J. Physiol. (Lond.) 119: 455-469.

Potter, D. D., S. C. Landis, S. G. Matsumoto, and E. J. Furshpan (1986) Synaptic functions in rat sympathetic neurons in microcultures. II. Adrenergic/cholinergic dual status and plasticity. J. Neurosci. 6: 10801090.

Price, J., and A. W. Mudge (1983) A subpopulation of rat dorsal root ganglion neurons is catecholaminergic. Nature 301: 241-243.

Reichardt, L. F., and P. H. Patterson (1977) Neurotransmitter synthesis and uptake by isolated sympathetic neurons in microcultures. Nature 270: 147-151.

Rohrer, H., A. L. Acheson, J. Thibault, and H. Thoenen (1986) Developmental potential of quail dorsal root ganglion cells analyzed in vitro and in vivo. J. Neurosci. 6: 2616-2624.

Schaeppi, U., and W. P. Koella (1964) Adrenergic innervation of the cat iris sphincter. Am. J. Physiol. 207: 273-279.

Siegel, R. E., M. Schwab, and S. Landis (1982) Developmental changes in the neuron's transmitter properties of sympathetic neurons in vivo. Soc. Neurosci. Abstr. 8: 7

Sjoqvist, F. (1963) Pharmacological analysis of acetylcholinesteraserich ganglion cells in the lumbo-sacral sympathetic system of the cat. Acta Physiol. Scand. 57: 352-362.

Sternberger, L. A., P. H. Hardy, J. J. Cuculis, and H. G. J. Meyer (1970) The unlabelled antibody enzyme method of immunohistochemistry. Preparation and properties of soluble antigen-antibody complex (horseradish peroxidase-antihorseradish peroxidase) and its use in the identification of spirochates. J. Histochem. Cytochem. 18: 315323

Teillet, M. A., P. Cochard, and N. M. LeDouarin (1978) Relative roles of the mesenchymal tissues and of the complex neural-tube notochord on the expression of adrenergic metabolism in ncural crest cclls. Zoon 6: $115-122$.

Teitelman, G., H. Baker, T. H. Joh, and D. Reis (1979) Appearance of catecholamine synthesizing enzymes during development of rat sympathetic nervous system: Possible role of tissue environment. Proc. Natl. Acad. Sci. USA 76: 509-513.

Teitelman, G., T. H. Joh, L. Grayson, D. H. Park, D. J. Reis, and L. Iacovitti (1985) Cholinergic neurons of the chick ciliary ganglion express adrenergic traits in vivo and in vitro. J. Neurosci. $5: 29-39$

Thibault, J., D. Vidal, and F. Gros (1981) In vitro translation of mRNA from rat pheochromocytoma tumors, characterization of tyrosine hydroxylase. Biochem. Biopharm. Res. Commun. 99: 960968.

Thoenen, H., and Y. A. Barde (1980) Physiology of nerve growth factor. Physiol. Rev. 60: 1284-1335.

Thoenen, H., P. U. Angeletti, R. Levi-Montalcini, and R. Kettler (1971) Selective induction by nerve growth factor of tyrosine hydroxylase and dopamine- $\beta$-hydroxylase in the rat superior cervical ganglia. Proc. Natl. Acad. Sci. USA 68:1598-1602.

Tosney, K. (1982) The segregation and early migration of cranial neural crest cells in the avian embryo. Dev. Biol. 89: 13-24.

Warwick, R. J. (1954) The ocular parasympathetic nerve supply and its mesencephalic sources. Anat. 88: 71-93.

Zigmond, R. E., and C. W. Bowers (1981) Influence of nerve activity on the macromolecular content of neurons and their effector organs. Annu. Rev. Physiol. 43: 673-687. 